\title{
Research on Enterprise Employee Demand Recognition Model Based on Kano and QFD
}

\author{
Ting Wang ${ }^{1, a}$, Wei Wang ${ }^{2, b,{ }^{*}}$, YuTong $\mathrm{Li}^{3, \mathrm{c}}$ and Guoxing Zhang ${ }^{4, \mathrm{~d}}$ \\ ${ }^{1234}$ School of Economics and Management, North China Electric Power University, No.619 Yonghua \\ Street, Baoding, Hebei 071003, China \\ a13932240065@139.com, ${ }^{b^{*}}$ qingdaowangw@163.com, \\ cyvettelee0712@Hotmail.com, d1260835527@qq.com
}

Key words: Quality Function Configuration, Kano model, Analytic Hierarchy Process, RM-MH Integration Method

\begin{abstract}
In this paper, the Kano model is modified by two-factor theory and Maslow's demand hierarchy theory, and set up construct HR-Kano model, than using the HR-Kano model to analyze the relationship between staff satisfaction and incentive policies, determine the type of staff requirements. an broader rating level to more clearly show that the relationship between the needs of staff and business goals between the strong correlation and weak correlation between the differences, finally provide an effective suggestion for the enterprise staff judgment and human resource management.
\end{abstract}

\section{Preface}

With the intensification of competition among enterprises, how to improve the enthusiasm and creativity of staff has become an effective way to win the enterprise. Different types of needs have different levels of impact on staff's satisfaction. The biggest difficulty in explaining the impact of different types of requirements on customer satisfaction is how to accurately and effectively understand the needs of staff. To this end, this paper introduces the HR-Kano model that describes the relationship between staff satisfaction and incentive measures, and improves the overall accuracy of HR-QFD construction by improving MH model. Put forward solutions about how to clarify the relationship between staff needs and corporate incentive policies.

\section{Application of QFD and Kano Model in Human Resources}

2.1 HR-QFD. Japanese scholar Akao Yoji first proposed the concept of QFD, have been adopted by a number of Japanese companies and quickly passed the United States and Europe. Later, the scope of application and field has been expanding, causing a wide range of academic and industrial research and application. The core of QFD is Quality House (HoQ) ${ }^{[1]}$, QFD uses the House of Quality to find ways and means to meet customer needs, so that products or services meet or exceed customer expectations ${ }^{[2]}$. In this paper, the QFD model is introduced into the enterprise human resource management and enterprise incentive policy. By analyzing the weight of the staff's demand and the enterprise incentive policy, we choose the staff incentive measures, which are effective and take the enterprise goal to realize the direction. 


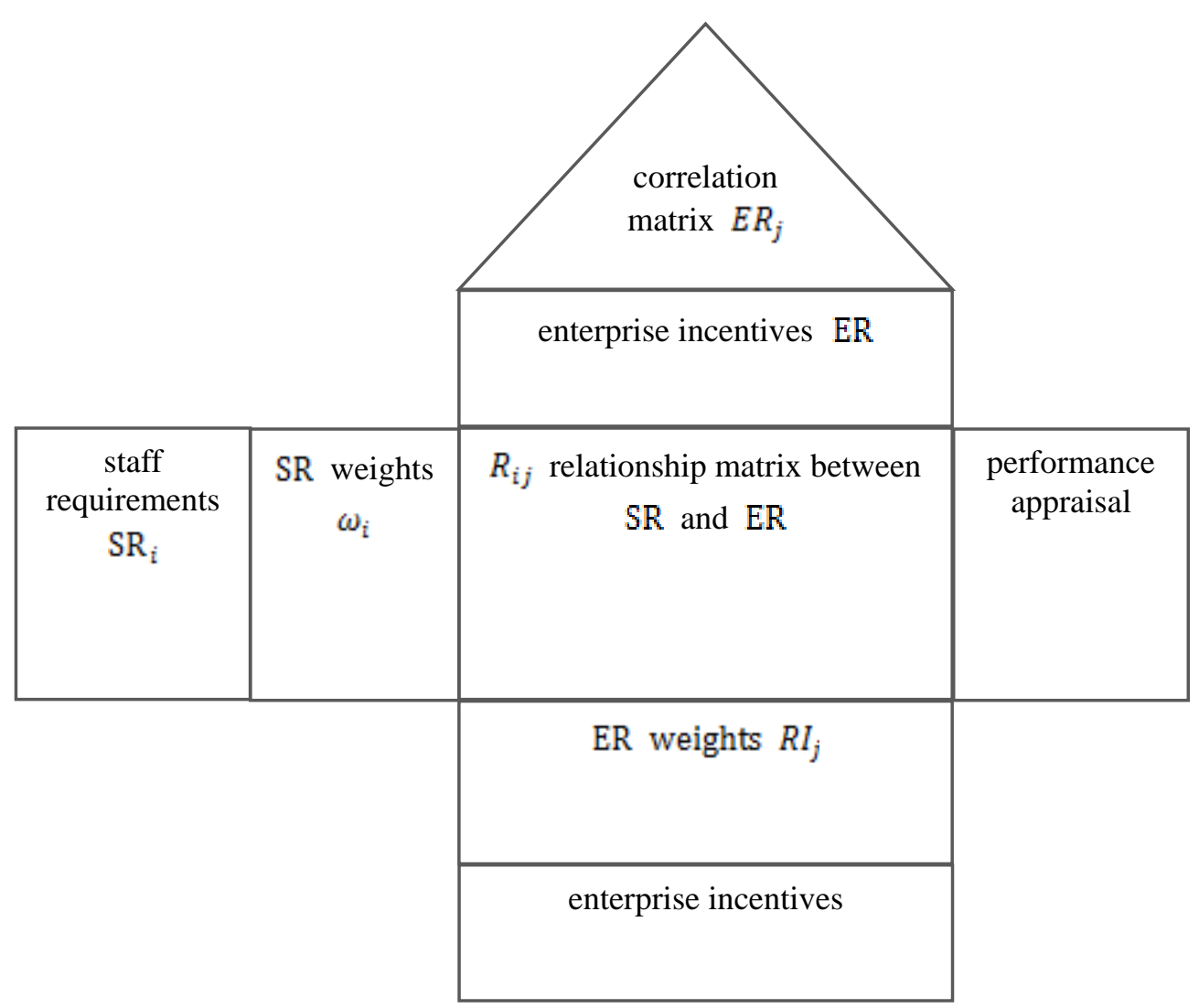

Figure $1 \mathrm{HR}$ demand house

$$
\sum_{i=1}^{m} \omega_{i}=1 \quad(1) A I_{j}=\omega_{i} R_{i j} \quad(2) \mathrm{RI}_{\mathrm{j}}=\mathrm{AI}_{\mathrm{j}} / \sum_{\mathrm{j}=1}^{\mathrm{n}} \mathrm{AI}_{\mathrm{j}}
$$

$\mathrm{SR}_{i}$ is staff's requirement; $E R_{j}$ is the decomposition of the relevant business after the $\mathrm{j}$ target characteristics; $\omega_{i}$ means relative importance; $R_{i j}$ relationship matrix between SR and ER, $A I_{j}$ is the absolute weight of $\mathrm{SR}_{i} ; R I_{j}$ is the relative weight of $\mathrm{SR}_{i} ; \mathrm{i}=1,2, \cdots, \mathrm{n}$ is the number of staff requirements, $\mathrm{j}=1,2, \cdots \mathrm{n}$ is the number of enterprise incentive policies and measures ${ }^{[3]}$.

2.2 HR-Kano Model. The Kano model is a model presented by Japanese quality management specialist Kano to determine whether a product or service meets customer needs. The model focuses on the relationship between customer satisfaction and product or service quality ${ }^{[4]}$.

In the theory of staff motivation based on social assumptions, in this paper, the HR-Kano model is proposed by modifying the Kano model by two-factor theory (incentive factor, health factor) ${ }^{\text {[5] }}$ and Maslow's demand hierarchy theory ${ }^{[6]}$. Pointed out that the needs of staff will be divided into six categories:

(1) Must-be Requirements: Basic needs equal to the two-factor theory of health care factors, can only eliminate people's dissatisfaction, but will not bring satisfaction, such as work safety, stability and so on.(2) One-dimensional Requirements: Staff satisfaction and job motivation are proportional to the degree to which this requirement such as staff salaries, working environment, is achieved. (3) Attractive Requirements: To meet the needs of self-realization of the staff, the realization of the demand can greatly improve the enthusiasm of the staff, such as business achievements, work autonomy. (4) Indifferent Requirements: Indifferent requirements are indifferent to the needs of staff. Regardless of whether the demand is met, and regardless of its degree of satisfaction, will not have an impact on staff. (5) Reverse Requirements: Something staff does not want to accept, the higher the frequency of such things will greatly affect the enthusiasm of the staff, such as unfair management policies within the enterprise. (6) Questionable Requirements: Needs that staff is not clear, feedback is wrong or difficult to achieve in the current stage. 


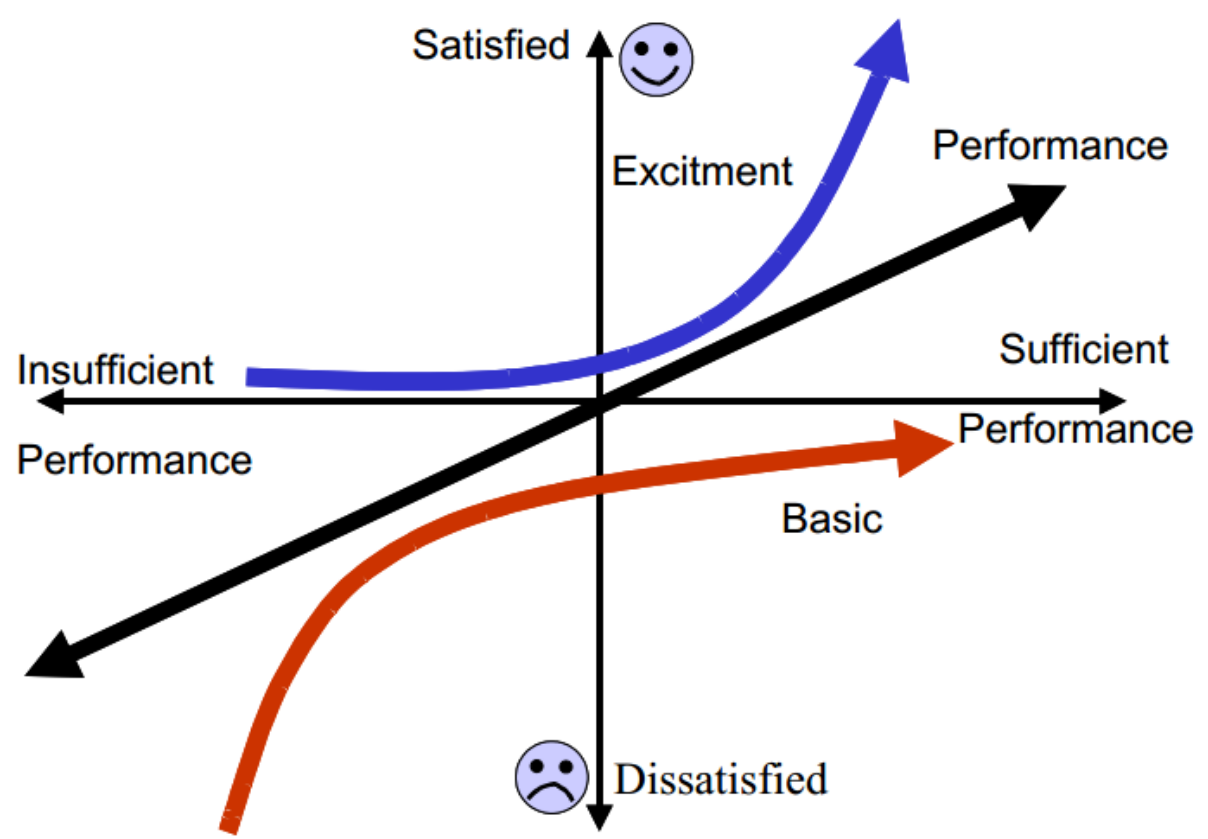

Figure 2 Kano model of excitement and basic quality

\section{Integrating of HR-QFD and HR-Kano Models}

3.1 HR-QFD and HR-Kano Model Algorithms. Matzler and Hinterhuber give the revised Kano model requirements classification assessment table, where: $\mathrm{M}$ denotes the Must-be Requirements; $\mathrm{O}$ denotes the One-dimensional Requirements; A denotes the Attractive Requirements; I denote the Indifferent Requirements; $\mathrm{R}$ denotes the Reverse Requirements; $\mathrm{Q}$ denotes the Questionable requirements ${ }^{[7]}$. This paper uses its assumptions to determine the type of staff needs and weight.

The data for the evaluation table are processed as Table 1 . For a certain $S R_{i}$, determine the type of demand according to the questionnaire of different staff, while assigning values to different types. such as Attractive Requirements (A) to 5, the One-dimensional requirements $(\mathrm{O})$ is assigned to 3, the Must-be Requirement (M) is assigned to 1, the Indifferent Requirement (I) assignment is 0, the Reverse Requirements (R) assignment is -3 , the Questionable Requirements $(\mathrm{Q})$ is set to 0. and the number of choices of each satisfaction degree is calculated for each valid questionnaire, and the absolute weight is calculated by the assignment.

$$
\begin{gathered}
R_{i}=n_{A} \times A+n_{O} \times O+n_{M} \times M+n_{I} \times I+n_{R} \times R+n_{Q} \times Q \\
\omega_{i}=A I_{i} / \sum_{i=1}^{m} A I_{i}
\end{gathered}
$$

Where, $R_{i}$ is the absolute importance of requirement $\mathrm{i}, \mathrm{n}_{A}:$ after the questionnaire is summarized, the requirement $\mathrm{i}$ is the number of attractive requirements. $\mathrm{n}_{0}:$ after the questionnaire is summarized, the requirement $\mathrm{i}$ is the number of one-dimensional requirements. $n_{M}$ : after the questionnaire is summarized, the requirement $\mathrm{i}$ is the number of Must-be requirements. $n_{l}$ : after the questionnaire is summarized, the requirement $\mathrm{i}$ is the number of indifferent requirements. $n_{R}:$ after the questionnaire is summarized, the requirement $i$ is the number of reverse requirements. $n_{Q}:$ after the questionnaire is summarized, the requirement $i$ is the number of questionable requirements. $\omega_{i}$ : the relative importance of the requirement $i$. 
Table 1 HR-Kano model requirements classification assessment table

\begin{tabular}{|c|c|c|c|c|c|c|}
\hline \multicolumn{2}{|c|}{ Question type } & \multicolumn{5}{|c|}{ Enterprises can not meet certain requirements } \\
\hline & & satisfied & $\begin{array}{l}\text { Should be } \\
\text { so }\end{array}$ & Indifferent & tolerable & $\begin{array}{c}\text { unsatisfie } \\
\text { d }\end{array}$ \\
\hline \multirow{5}{*}{$\begin{array}{c}\text { Enterpris } \\
\text { es can } \\
\text { meet a } \\
\text { certain } \\
\text { demand }\end{array}$} & satisfied & $\mathrm{Q}$ & $\mathrm{A}$ & A & A & $\mathrm{O}$ \\
\hline & Should be so & $\mathrm{R}$ & I & I & I & M \\
\hline & indifferent & $\mathrm{R}$ & I & I & I & M \\
\hline & tolerable & $\mathrm{R}$ & $\mathrm{I}$ & I & I & $\mathrm{M}$ \\
\hline & unsatisfied & $\mathrm{R}$ & $\mathrm{R}$ & $\mathrm{R}$ & $\mathrm{R}$ & Q \\
\hline
\end{tabular}

3.2 RM-MH Method Implementation Steps. Based on the previous analysis, this based on interhuber in 1998 proposed a Kano model and QFD integration method (referred to as MHMatzler and $\mathrm{H}$ method) proposed staff needs to determine the method (RM-MH), the specific steps are as follows:

(1) Prepare a questionnaire and conduct a staff needs survey;

(2) Analyze the survey results, according to the HR-Kano model to the staff needs to be classified;

(3) Using the formula (3) (4) to get $\omega_{i}$;

(4) identify and determine the relationship matrix between SR and ETR;

(5) Use the formula (1) (2) and HR-QFD graphics to determine the relative weights.

\section{Case Analysis}

A enterprises to improve staff enthusiasm, to take the following six measures to encourage. (1) to increase safety education, staff training, (2) the establishment of office rest area, (3) improve performance bonuses, (4) the establishment of psychological counseling room, (5) to increase attendance assessment efforts, (6) corporate culture training. And that fifty employees were surveyed by HR-Kano Model Needs Assessment Form and calculated on the basis of the survey results.

Table 2 Employee Satisfaction Weight

\begin{tabular}{ccccccc}
\hline Demand & 1 & 2 & 3 & 4 & 5 & 6 \\
\hline$R_{i}$ & 201 & 115 & 46 & 11 & -91 & 5 \\
\hline$\omega_{i}$ & 0.70 & 0.40 & 0.16 & 0.04 & -0.32 & 0.02 \\
\hline$R_{i j}=\left(\begin{array}{llllll}0.1 & 0.15 & 0.43 & 0.05 & 0.15 & 0.12\end{array}\right)$
\end{tabular}

According to formula (2) (3), The results obtained are shown in Table 3.

According to this analysis results, it can clearly find enterprise incentives (1) is to meet the Must-be Requirements of employees, with largest value of $R I_{1}$. which will meet the business operation, and achieve the basic guarantee of corporate profits. Followed by incentives (3) which improves staff performance bonuses and meets the Attractive Requirements of employees, it can also greatly improve the enthusiasm of staff that is conducive to business goals. And the value of $R I_{5}$ for the measure (5) is negative, that change measures will cause staff resentment, is not conducive to improving the enthusiasm of the staff work. 
Table 3 ER weights $R I_{j}$

\begin{tabular}{lllllll}
\hline Demand & 1 & 2 & 3 & 4 & 5 & 6 \\
\hline$A I_{j}$ & 0.070 & 0.060 & 0.069 & 0.002 & -0.048 & 0.002 \\
\hline$R I_{j}$ & 0.45 & 0.39 & 0.44 & 0.01 & -0.31 & 0.01 \\
\hline
\end{tabular}

\section{Conclusion}

In this paper, through in-depth study of product quality management in the Kano model and product quality QFD management methods, combined with demand theory to explore its application in human resources management, this article presents a method (RM-MH) of identifying the relationship between employee needs and business incentives, which integration by HR-QFD and HR-Kano models. Through the analysis of the incentive measures of Company A, the results of the surface of the method can clearly identify the relationship between business measures and staff needs, as well as the strong correlation between firm employee needs and corporate goals.

\section{References}

[1] S. K. Goyal, An integrated inventory model for a single supplier-single customer problem, International Journal of Production Research, vol.15, pp. 107-111, 1977.

[2] Stephen Murgatroyd, The house of quality: Using QFD for instructional design in distance education, American Journal of Distance Education, vol.7.2, pp. 34-48, 1993.

[3] Yoon-Eui Nahm, Haruo Ishikawa, Masato Inoue, New rating methods to prioritize customer requirements In QFD within complete customer preferences. Int J Adv Manuf Technol, vol.65, pp. 1587-1604, 2013.

[4] Md Mamunur Rashid1, A Kano Model Based Linguistic Application for Customer Needs Analysis, International Journal of Engineering Business Management, Vol. 3, pp. 2, 2011.

[5] Tontini G. Integrating the Kano Model and QFD for Designing New Products. Total Quality Management \& Business Excellence, vol. 18(6), pp. 599-612, 2007.

[6] Engle, Randall W, and M. J. Kane. Executive Attention, Working Memory Capacity, and a Two-Factor Theory of Cognitive Control. Psychology of Learning \& Motivation, vol.44.03, pp. 145-199, 2003.

[7] Wahba, Mahmoud A., and L. G. Bridwell. Maslow reconsidered: A review of research on the need hierarchy theory. Organizational Behavior \& Human Performance, vol.15.2, pp. 212-240, 1976. 